\title{
LA MEDIACIÓN PREVISTA EN EL ART. 190 DE LA CONSTITUCIÓN ECUATORIANA, COMO MEDIO ALTERNATIVO DE SOLUCIÓN DE CONFLICTOS FAMILIARES, APLICADA A TRAVÉS DEL CENTRO NACIONAL DE MEDIACIÓN DE LA FUNCIÓN JUDICIAL.
}

\author{
THE MEDIATION PROVIDED FOR IN ARTICLE 190 OF THE \\ ECUADORIAN CONSTITUTION, AS AN ALTERNATIVE MEANS OF \\ SOLVING FAMILY DISPUTES, APPLIED THROUGH THE NATIONAL \\ CENTER FOR MEDIATION OF THE JUDICIAL FUNCTION
}

\author{
Dionicio Gerardo Jumbo Quezada ${ }^{1}$ \\ jet120465@hotmail.com \\ Oscar Vélez Mora ${ }^{2}$ \\ oscar.velezm@ug.edu.ec \\ Yamil De Haz Cruz $^{2}$ \\ angela.dehazc@ug.edu.ec \\ ${ }^{1}$ Foro de Abogados. Guayaquil-Ecuador. \\ 2Universidad de Guayaquil, Ecuador.
}

\section{RESUMEN}

En el presente trabajo de investigación, se analizó una importante situación jurídica que está atravesando nuestra sociedad ecuatoriana, como es la aplicación de la Mediación en la solución de conflictos, especialmente familiares, en el cual se propone reformas que ofrezcan profundizar y mejorar el servicio público de justicia, a través de mecanismos alternativos más agiles y simplificados como lo es la mediación pre-procesal e intra-procesal. Los datos recogidos fueron analizados en términos estadísticos a través de frecuencias, porcentajes y aplicación de pruebas de asociación entre variables de tipo: histórica, exploratoria y documental. El resultado de este trabajo es de tipo jurídicoconstitucional y social, para coadyuvar a la divulgación de dicho postulado constitucional por considerarlo válido, útil y necesario; a la vez que formular propuestas de reformas a ciertas leyes, y diseñar herramientas que aborden esta problemática en aras de contribuir a la disminución de la violencia intra y extra familiar, que de una u otra forma también afecta al sumak kawsay o buen vivir, que es parte del nuevo proyecto social de vida de nuestro país.

Palabras clave: Mediación, Procedimiento, Conflicto, Solución

\begin{abstract}
In this research, we analyzed an important legal situation that is going through our Ecuadorian society, such as the application of mediation in the solution of conflicts, especially family conflicts, which proposes reforms that offer to deepen and improve the public service of justice, through more agile and simplified alternative mechanisms such as pre-procedural and intra-procedural mediation. The data collected were analyzed in statistical terms through frequencies, percentages and application of evidence of association between variables of type: historical, exploratory and documentary. The result of this work is of juridical-constitutional and social type, in order to contribute to the disclosure of said constitutional postulate as valid, useful and necessary; At the same time as formulating proposals for reforms to certain laws, and to design tools that address this problem in order to contribute to the reduction of intra and extra-family violence, which in one way or another also affects sumak kawsay or good living, which Is part of the new social project of life of our country.
\end{abstract}

Keywords: Mediation, Procedure, Conflict, Solution

Recibido: 28 de noviembre de 2016

Aceptado: 10 de julio de 2017

Publicado: 31 de julio de 2017 


\section{Introducción}

La Mediación como el término mismo lo denota, es un medio de solución de conflictos en general, aplicable también a los conflictos familiares porque puede ayudar a las parejas unidas por matrimonio o unión libre en momentos de crisis, solucionar sus problemas partiendo de sus propias formas de ver las cosas. Entonces la mediación familiar es un método de resolución alternativa de conflictos en el que un tercero neutral llamado generalmente "mediador" ayuda a las parejas, personas o grupos implicados en el conflicto a lograr soluciones satisfactorias para todos los miembros del núcleo familiar. El papel del mediador es dirigir el proceso, manteniéndose neutral respecto del resultado e imparcial entre las partes, por esta razón no ofrece su opinión ni da consejos en ningún sentido, respeta el protagonismo de los interesados en la consecución de acuerdos y en su cumplimiento. Por ello la mediación y en particular la familiar, produce mayor satisfacción que otros métodos de resolución de conflictos como la conciliación, el arbitraje, los jueces de paz, etc.
La mediación familiar se inició, en la segunda mitad de la década de los años 70 del siglo $X X$ pasado, en Estados Unidos de Norteamérica y con el tiempo ha ido extendiéndose a otros países y por ende llegó al Ecuador. La Mediación Familiar surgió para intentar dar una salida extrajudicial al gran número de separaciones y divorcios por distintas causas, que colapsan el sistema judicial.

Esto se da porque a los miembros que son cabeza de familia les falta tiempo, un espacio y el lugar adecuado para hablar, escuchar, para entenderse con la pareja, con los hijos y demás parientes al menos cercanos. Poco a poco, la sociedad en continuo crecimiento ha ganado independencia, autonomía, sabiduría, competitividad, pero ha perdido en el camino algo importante, que aún se puede apreciar en poblaciones pequeñas, como son los valores morales, éticos, y los principios de la solidaridad, el compañerismo, la comprensión, el entendimiento y otros. Los Centros de Mediación públicos o privados y los mediadores en particular, procuran dar el espacio para que esa comunicación fluya, pero ¿sabemos de la existencia de dichos centros?, al parecer muy poco.

\section{Cuadro $N^{\circ}$ 1: Causas y Consecuencias}

\begin{tabular}{|c|c|}
\hline CAUSAS & CONSECUENCIAS \\
\hline $\begin{array}{l}\text { Bajo nivel educativo de la mayoría de la población de } \\
\text { escasos recursos económicos. }\end{array}$ & $\begin{array}{l}\text { Impide una mejor comprensión del entorno } \\
\text { socio-económico y familiar en el que se } \\
\text { desenvuelven y desarrollan día a día. }\end{array}$ \\
\hline $\begin{array}{l}\text { Insuficiente conocimiento de la ciudadanía sobre sus } \\
\text { derechos y obligaciones como miembros del núcleo } \\
\text { familiar }\end{array}$ & Genera violencia intra y extra familiar \\
\hline $\begin{array}{l}\text { Poca acogida y trascendencia de la Mediación en } \\
\text { los medios de comunicación social con } \\
\text { preeminencia de programas y noticias incitadoras a } \\
\text { la violencia }\end{array}$ & $\begin{array}{l}\text { Incentiva la cultura del conflicto, del poder } \\
\text { del más fuerte sobre el más débil, del morbo } \\
\text { sensacionalista. }\end{array}$ \\
\hline $\begin{array}{l}\text { Escasa motivación de los abogados en libre ejercicio } \\
\text { para direccionar sus casos familiares a la Mediación } \\
\text { prejudicial y no obstaculizar la mediación } \\
\text { intraprocesal }\end{array}$ & $\begin{array}{l}\text { Los ciudadanos no tienen la oportunidad de } \\
\text { al menos intentar la mediación en litigios } \\
\text { familiares }\end{array}$ \\
\hline $\begin{array}{l}\text { Ausencia de infraestructura suficiente y adecuada } \\
\text { tanto en la función judicial como en otras } \\
\text { instituciones públicas, semipúblicas y privadas para } \\
\text { los usuarios. }\end{array}$ & $\begin{array}{l}\text { Imposibilidad de que los ciudadanos se } \\
\text { motiven o acepten acudir a los pocos } \\
\text { centros de mediación existentes }\end{array}$ \\
\hline $\begin{array}{l}\text { Falta de más oportunidades laborales dependientes } \\
\text { y autónomas para los miembros familiares de la } \\
\text { población económicamente activa (PEA) }\end{array}$ & $\begin{array}{l}\text { Aumentan las carencias materiales que } \\
\text { incitan a la violencia infra familiar y social }\end{array}$ \\
\hline
\end{tabular}

\section{Aspectos Metodológicos}

En este trabajo se acude a la Investigación de tipo: Histórica, exploratoria y documental.
Según Bernal, en la ciencia existen diferentes tipos de investigación y es necesario conocer sus características para saber cuál de ellos se 
ajusta mejor a la investigación que va a realizarse.

La investigación histórica, según Bernal, en general, y siguiendo a Salkind (1998; pág. 12) "la investigación histórica se orienta a estudiar los sucesos del pasado. Analiza la relación de esos sucesos con otros eventos de la época y con sucesos presentes". En síntesis, se busca entender el pasado y su relación con el presente y el futuro. La investigación exploratoria, según Bernal, pretende darnos una visión general, de tipo aproximativo, respecto a una determinada realidad. Este tipo de investigación se realiza especialmente cuando el tema elegido ha sido poco explorado y reconocido, y cuando más aún, sobre él, es difícil formular hipótesis precisas o de cierta generalidad. Suele surgir también cuando aparece un nuevo fenómeno que por su novedad no admite una descripción sistemática o cuando los recursos del investigador resultan insuficientes para emprender un trabajo más profundo. La investigación documental, según Bernal, consiste en un análisis de la información escrita sobre un determinado tema, con el propósito de establecer relaciones, diferencias, etapas, posturas o estado actual del conocimiento respecto al tema objeto de estudio.

Aunque las fuentes documentales son muy variadas, se tomaron básicamente: documentos escritos como libros, revistas y actas de acuerdos conciliatorios de la temática.

\section{Tipos de Conflictos}

Existen diversas clases o tipos de conflictos y varios criterios de clasificación, por lo que en este trabajo, lo hago siguiendo la tendencia de aquellos sujetos o personas que intervienen, pudiendo ser entre dos individuos o entre grupos de individuos.

Criterio 1: de personas que intervienen en ellos:

a) Conflictos personales;

b) Conflictos entre grupos.

Criterio 2: Conflictos de índole ideológica:

a) Conflictos por ideologías políticas y sociales divergentes.

b) Conflictos religiosos.

c) Conflictos filosóficos.

d) Conflictos políticos.

Criterio 3: Conflictos armados:

a) Conflictos interestatales.

b) Conflictos armados interestatales 0

internacionales.

c) Conflictos armados no gubernamentales.

d) Conflictos extraestatales.

\section{Otros tipos de conflictos más comunes:}

a) Conflictos Familiares.- Son los que afectan a una de las instituciones más importantes y más antiguas de la sociedad como es la familia, y cuando nos encontramos con problemas en este núcleo, ya sean de tipo económico o de estabilidad material, de vivienda, de falta de padres o cuando la familia está a la deriva o sin una dirección clara estamos en presencia de un conflicto familiar. Si estos conflictos se repiten de manera indiscriminada en un país o territorio esto afectará a toda la sociedad.

b) Conflictos laborales.

c) Conflictos económicos.

d) Conflictos de interés.

Algunos conflictos según su extensión:

a) Conflictos locales.

b) Conflictos regionales.

c) Conflictos globales.

\section{Medios Alternativos de solución de conflictos (MASC)}

Los medios alternativos a los procesos judiciales, para la solución de conflictos en el Ecuador son: Arbitraje, Conciliación, Mediación y Otros; sobre estos últimos medios y para fines de este trabajo se considera únicamente a los Jueces de Paz.

Arbitraje.- Procedimiento extrajudicial para resolver conflictos de intereses mediante sometimiento de las partes, por mutuo acuerdo, a la decisión de uno o varios árbitros.

Conciliación.- Acuerdo de los litigantes para evitar un pleito o desistir del ya iniciado.

Mediación.- Actividad desarrollada por una persona de confianza de quienes sostienen intereses contrapuestos, con el fin de evitar o finalizar un litigio.

Jueces de Paz.- Persona que hasta la institución de los municipales, en 1870, oía a las partes antes de consentir que litigasen, procurando reconciliarlas, y resolvía de plano las cuestiones de ínfima cuantía. También, cuando era letrado, solía suplir al juez de primera instancia. La Mediación es un proceso dirimente y conciliador para los conflictos de familia, a diferencia del arbitraje que es más formal para resolver disputas post divorcio o terminación de la unión libre, incluyendo cláusulas. Este último también reduce la posibilidad de alargar el litigio judicial, es decir alienta a negociar desacuerdos por la 
existencia de cláusulas y un árbitro neutral, lo que no se da en la mediación.

\section{La mediación Familiar}

La Mediación en general es un método y/o mecanismo (medio) de solución de conflictos en los distintos ámbitos del quehacer humano individual o colectivo (social), en el cual un tercero imparcial busca facilitar la comunicación para que las partes por sí mismas sean capaces de resolver un conflicto, sin necesidad de ir al ámbito judicial, o sea sin judicializar el caso, en cuya circunstancia la solución puede ser traumática incluso para las dos partes.

Dicho medio alternativo de solución de conflictos, con su procedimiento particular, es plenamente aplicable en el ámbito familiar; cuyos procesos específicos implican un enfoque sistémico porque se trabaja con un sistema socio-familiar formado a partir de dos personas, que se basa en los principios básicos de voluntariedad, confidencialidad, transparencia, respeto mutuo, entre otros. En cualquier caso, se desarrolla en un ámbito noterapéutico.

La mediación familiar se desarrolla ampliamente en la mayoría de los países anglosajones a finales del siglo XX: Estados Unidos, Canadá, Reino Unido, Australia y Nueva Zelanda.

En Iberoamérica los países donde más se ha desarrollado y normativizado esta disciplina son España, Chile y Argentina, aunque también existen experiencias reconocidas por iniciativa privada, en la última década, en otros países como: México, Colombia y Brasil.

\section{Principios de la Mediación Familiar}

La Mediación respecto a las partes, se basa en los principios de: intervención libre y voluntaria (voluntariedad), la confidencialidad, la transparencia, el respeto mutuo, la buena fe, la intervención cooperativa, así como en su carácter personalísimo. Todas las Leyes de los países que la han desarrollado, conciben la mediación familiar bajo el principio de la libertad de las partes para acceder a ella. Sin embargo, esa libertad no pueden ejercerla si desconocen que existe $o$ en qué consiste la mediación familiar, pues la suelen confundir con su similar la conciliación y otros medios o servicios públicos como los Jueces de Paz, que procuran el mismo fin. Nótese que el principio de voluntariedad es uno de los puntos característicos fuertes de la mediación, el cual es incuestionable e insustituible dentro de este proceso.

En líneas generales, las Leyes que tratan de la mediación tienen unos criterios parecidos en cuanto a las características del proceso de mediación. Los derechos y deberes que ha de cumplir el mediador y las partes; la creación de un Registro para su inscripción y un régimen sancionador. Respecto a los acuerdos de mediación, en caso de alcanzarse, el sistema que se sigue suele ser el de indicar que esos acuerdos serán válidos y obligarán a las partes que los hayan firmado, siempre que en ellos concurran los requisitos necesarios para la validez de los contratos.

El acuerdo en mediación familiar no tiene porqué ser necesariamente justo desde el punto de vista jurídico. A diferencia de un proceso de conciliación, el mediador facilita un acuerdo consensuado entre las partes que según nuestra legislación luego de suscrito y formalizado sí tiene obligatoriedad jurídica de cumplimiento mediante su ejecución a través de un juez de derecho, y que está basado en optimizar los pactos a los que las partes están dispuestas a llegar por el beneficio mutuo, mientras que el conciliador define unilateralmente un acuerdo tras haber escuchado a las partes, basado en principios de justicia e imparcialidad que emanan del Derecho, estableciéndose también la obligatoriedad para su cumplimiento pero hasta ahora siempre dentro de un proceso judicial o administrativo (intraprocesal).

\section{Principios universales de la familia}

Para introducirnos en el tema de los principios universales de la familia, primero debemos conocer que al hacer referencia a principios conocemos etimológicamente que proviene del latín principium que significa comienzo, primera parte o parte principal, y en el sentido moral "principio" representa a un conjunto de valores que orientan y norman la conducta de una sociedad concreta, además que en el sentido jurídico es como un axioma o fundamento lógico.

Entonces, si nos referimos a los principios o valores universales de la familia debemos retomar un poco la historia de la humanidad en un sentido objetivo y positivo, donde los seres humanos transforman la naturaleza, crean, opinan y se comunican entre sí sólo como miembros de un grupo social; muchos hombres se destacan por su participación en 
acontecimientos trascendentes o significativos para las páginas de nuestra historia y sociología.

Sabemos que la ciencia que estudia al hombre, su origen, comportamiento, evolución, desarrollo y características generales en una sociedad, es la historia; disciplina que enfoca al hombre desde la aparición de las primeras culturas y comunidades hasta nuestros días; esta ciencia nos permite conocer el proceso social, cultural y el estilo de todas y cada una de las sociedades que han existido y existen en la Tierra, los hechos más importantes y el modus vivendi de épocas anteriores. Valores universales de la familia que son el conjunto de normas de convivencia válidas en un tiempo y época determinada.

Estos valores ante la solución del dilema, no son sencillos; lo que se debe a que en ocasiones se confrontan valores importantes y entran en conflicto. ¿Cuáles? Por ejemplo el derecho a la vida y a la salud, el respeto a la propiedad privada, la observancia de las leyes, etcétera.

Un concepto decisivo y estrechamente ligado a los valores, es el de la "actitud". ¿Qué son las actitudes? Son tendencias adquiridas que predisponen a una persona a reaccionar de un modo determinado ante un objeto, persona, suceso o situación, y actúa en consecuencia. Una de éstas es la "opinión", que es la manifestación pública, por lo general verbalizada, de un sentimiento o creencia. Expresa un valor o una actitud. Otro concepto relevante es el "hábito" que es un comportamiento o modo de proceder en forma regular, normal y adquirido por la repetición de actos similares.

\section{La mediación familiar en el Ecuador, Antecedentes Jurídicos}

En tiempos remotos se atisba la mediación a través de un tercero neutral que era el jefe de la comunidad, pero con en el recurrir del tiempo todo se transformó aludiendo a la legislación para alcanzar los derechos.

La constitución del Ecuador de 1978 codificada en $1997^{1}$ no señala con exactitud a la Mediación, pero sí abre la posibilidad de considerarla al reconocer el sistema arbitral, la negociación y otros procedimientos alternativos para la solución de las controversias.
La primera ley $(\mathrm{s} / \mathrm{n})$ de arbitraje y mediación, publicada en el Registro Oficial $\mathrm{N}^{\circ} 145 \mathrm{del} 4 \mathrm{de}$ septiembre de 1997 desarrolla en algo a la mediación como procedimiento de solución de conflictos y la libertad de acceder a ella, en su Título II, Art. 44 inciso segundo.

Los Principios de la Constitución de la República del Ecuador de 2008 formalizan la utilización de procedimientos alternativos para dirimir bajo solución pacifica, conflictos que puedan surgir entre personas naturales que incluye a la familia, personas jurídicas, públicas o privadas y todo lo que en contexto pueda generar relación jurídica, mitigando y atenuando a través de la implementación del diálogo y la concertación, una mejor convivencia social, todo esto en aras del desarrollo cultural de nuestro país; puesto que la mediación es también hacer cultura de paz para la familia y por ende para la sociedad.-

\section{Evolución cronológica de la legislación ecuatoriana sobre mediación}

1.- Ley de Arbitraje Comercial dictada mediante Decreto Supremo № 735 de 23 de octubre de 1963 y publicada en el Registro Oficial № 90 de 28 de octubre de 1963, derogada por la siguiente Ley.

2.- Ley $s / n$, de Arbitraje y Mediación, publicada en el Registro Oficial $N^{\circ} 145$ del 4 de septiembre de 1997.

3.- Constitución Política de la República publicada el 11-08-1998, derogada.

4.- Código de la Niñez y Adolescencia, publicado en el Registro Oficial № 737 del 3 de enero del 2003; actualmente categorizado como orgánico.

5.- Ley $N^{\circ} 2005-48$, publicada en el Registro Oficial $\mathrm{N}^{\circ} 532$ del 25 de febrero de 2005.

6.- Código Civil, codificación publicada en el Suplemento del Registro Oficial $N^{\circ} 46$ del 24 de junio de 2005.

7.- Código de Procedimiento Civil, codificación publicada en el Suplemento del Registro Oficial $N^{\circ} 58$ del 12 de julio de 2005.

8.- Ley Orgánica del Ministerio Público, codificación publicada en el Registro Oficial № 250 del 13 de abril de 2006, actualmente derogada.

9.- Codificación N²006-014 de la Ley de Arbitraje y Mediación, publicada en el Registro Oficial \# 417 de 14-XII-2006.

\footnotetext{
${ }^{1}$ Art. 118 inciso $3^{\circ}$ : Se reconoce el sistema arbitral, la negociación y otros procedimientos alternativos para la solución de las controversias.
} 
10.- Ley $s / n$ publicada en el Suplemento del Registro Oficial 544 de 9-III-2009, reformatoria del Código Orgánico de la Función Judicial.

11.- Código Orgánico Integral Penal, publicado en Registro Oficial Suplemento 180 de 10feb.-2014, modificado el 14-07-2014 por tabla del CONSEP, Registro Oficial Suplemento 288, página 3.

12.- Código Orgánico General de Procesos, Registro Oficial Suplemento \# 506 de 2205-2015.

\section{La Mediación en la Constitución de la República del Ecuador de 2008}

Nuestra actual Constitución, elaborada, discutida y aprobada por una Asamblea Constituyente y luego ratificada mayoritariamente por el pueblo ecuatoriano mediante consulta popular, fue publicada en el Registro Oficial $\mathrm{N}^{\circ} 449$ del 20-10-2008, la misma que refiere sintetizadamente sobre la Mediación en su artículo 190 al estipular que:

"Se reconoce el arbitraje, la mediación y otros procedimientos alternativos para la solución de conflictos. Estos procedimientos se aplicarán con sujeción a la ley, en materias en las que por su naturaleza se pueda transigir.

En la contratación pública procederá el arbitraje en derecho, previo pronunciamiento favorable de la Procuraduría General del Estado, conforme a las condiciones establecidas en la ley."

Dicho postulado es parte del Título IV Participación y Organización del Poder, Capítulo Cuarto, Función Judicial y Justicia Indígena, Sección Octava: Medios alternativos de solución de conflictos.-

La Constitución reconoce que la Mediación es uno de los métodos más viable para enfrentar los problemas que tiene la justicia ordinaria en los despachos de las causas, la lentitud de los trámites del proceso y Jueces que no estaban provistos de experiencia suficiente para enfrentar los retos que conlleva el manejo de los conflictos familiares en el diario vivir. Por tal motivo la gente ha perdido la fe y ven con buenos ojos a la Mediación como un instrumento jurídico viable para resolver de manera rápida los temas en disputa.

\section{Resultados}

Los resultados obtenidos en las variables relacionadas con información sociodemo- gráfica y Psicosocial los antecedentes de la historia de vida (nivel educacional, situación laboral, experiencias de violencia y problemas asociados a la violencia en familia de origen) se plantean anteproyectos de reformas a la Ley de Arbitraje y Mediación, al Código Orgánico de la Niñez y Adolescencia y al Código Orgánico de la Función Judicial, que permitan a los jueces de familia de primer nivel, imponer sutilmente de oficio a las partes, que acudan a mediación familiar, sin lesionar sus derechos fundamentales, por el beneficio potencial a sus miembros.

En la elaboración de esta propuesta investigativa para ampliar el uso de un "medio alternativo al procedimiento judicial ordinario para la solución de conflictos familiares en el ecuador" se formulan los siguientes textos reformatorios a los artículos pertinentes a la mediación aplicado específicamente al ámbito familiar, a saber:

1.- A la Ley de Arbitraje y Mediación vigente, en el Art. 46 literal c) inciso primero, suprímase la frase "siempre que las partes lo acepten", y la coma (,) que le precede.

2.- Al Código Orgánico de la Niñez y Adolescencia en su Libro Tercero, Título XI: DE LA MEDIACIÓN, después del Artículo 296 agregar uno que diga: "Art.- En los Centros de Mediación públicos 0 privados legalmente autorizados, deberán existir mediadores especializados en asuntos de conflictos familiares; sin perjuicio de la facultad que tengan las Junas Cantonales de Protección de derechos de los niños, niñas y adolescentes".

Y en el Art. 297, sustitúyase la frase "especial sobre la materia", por la frase "de Arbitraje y Mediación".- Y antes del punto final del artículo, agregar: ", y el Código Orgánico General de Procesos".

3.- En el Art. 130 № 11 del Código Orgánico de la Función Judicial, refórmese lo siguiente:

El texto que va desde el primero punto (.) seguido hasta el final del mismo, sustitúyase por lo siguiente: "De considerarlo conveniente los tribunales o juezas y jueces podrán disponer de oficio que pasen los procesos a un Centro de Mediación intraprocesal público o privado, legalmente autorizado, con la misma finalidad, en cuyo caso se suspenderá la competencia".

Al analizar los resultados obtenidos de la encuesta y vistas las estadísticas se determina que hasta la fecha, la mediación ha tenido poca acogida por lo que pretendo con esta propuesta legal, motivar a la conciencia ciudadana para que por intermedio de sus representantes en la Asamblea Nacional, y sus directivos como 
voceros autorizados acojan la misma para su apoyo y aprobación siguiendo el procedimiento ordinario de creación de la Ley.

Esto porque la propia Constitución obliga al cumplimiento del deber de defensa del orden democrático y el poder legítimamente constituido que no se circunscribe tan sólo al ejercicio del sufragio por parte de los ciudadanos, sino que se amplía con el derecho a la participación ciudadana en el proceso de formación de una Ley o reforma de la misma, que se resume en lo siguiente:

Para la presentación de Proyectos de Ley, existen 11 pasos que son los requeridos para su aprobación, lo cual permite a todos los ecuatorianos dentro y fuera del territorio ser partícipes de la construcción del Ecuador que queremos y merecemos.

Según el Art. 134 de la Constitución, la iniciativa para presentar proyectos de ley corresponde:

A las y los asambleístas, con el apoyo de una bancada legislativa o de al menos el cinco por ciento de los miembros de la Asamblea Nacional.

A la Presidenta o Presidente de la República.

A las otras funciones del Estado en los ámbitos de su competencia.

A la Corte Constitucional,

A la Procuraduría General del Estado,

A la Fiscalía General del Estado,

A la Defensoría del Pueblo, y

A la Defensoría Pública, en las materias que les corresponda de acuerdo con sus atribuciones.

A las ciudadanas y los ciudadanos que estén en goce de los derechos políticos y a las organizaciones sociales que cuenten con el respaldo de por lo menos el cero punto veinticinco por ciento de las ciudadanas y ciudadanos inscritos en el padrón electoral nacional.

Quienes presenten proyectos de ley de acuerdo con estas disposiciones podrán participar en su debate, personalmente o por medio de sus delegados.

Los proyectos de ley deberán referirse a una sola materia y serán presentados a la Presidenta o Presidente de la Asamblea Nacional con la suficiente exposición de motivos, el articulado que se proponga y la expresión clara de los artículos que con la nueva ley se derogarían o se reformarían.
Si el proyecto no reúne estos requisitos no se tramitará

\section{Conclusiones}

Los principales resultados de este estudio permiten afirmar que la gran mayoría de las parejas estudiadas ha utilizado la violencia como estrategia de resolución de conflictos en sus diversas manifestaciones; utilizando, mayormente, violencia psicológica, verbal y, en un porcentaje, menor violencia física; por lo que se arriba a las siguientes conclusiones:

1.- Falta redefinir el rol de la mediación para comprender su filosofía, y dar paso a que los ciudadanos conozcan la existencia de la mediación, como otro proceso más que pueden utilizar, si así lo desean, para negociar sus desacuerdos, antes de iniciar un litigio judicial.

2.- Así como la Unión Europea pide a sus Estados miembros que alcancen unos estándares mínimos de calidad en la prestación de los servicios de mediación, en Suramérica y en el Ecuador en particular se debe adoptar las acciones y medidas necesarias para ampliar la utilización de la mediación en los diversos problemas de la familia ampliada.

3.- Aplicar un Código ético-deontológico único obligatorio para todos los mediadores del país, para que no se trastornen los principios de la mediación, y haya una garantía que asegure su calidad.

4.- Reformar las normas que regulan la Mediación en las diferentes leyes para que la fase de pre-mediación sea preceptiva, ya que en nada se contrapone al principio de voluntariedad que ha de imperar.

5.- Exigir formación universitaria y específica en la materia a los Mediadores y demás profesionales que se dediquen a la Mediación, para que esta Institución goce de fiabilidad y calidad; categorizándola al nivel de estudios de postgrado/master; con capacitación permanente.

6.- Permitir que los Gobiernos Autónomos Descentralizados Municipales implementen Centros de Mediación Comunitaria, siempre bajo la supervisión del Consejo de la Judicatura.

7.- Promover la difusión de la mediación familiar para facilitar a los ciudadanos el conocimiento de las ventajas y características de esta institución, a fin de conseguir su reconocimiento social como instrumento válido para la solución y resolución de los conflictos familiares en el Ecuador. 
8.- La Dictación de un Código de Familia que compendie la dispersa legislación relacionada con la familia, donde se desarrolle ampliamente la mediación.

\section{BIBLIOGRAFÍA}

1. Bueno Carlos, La formación del abogado y los problemas del ejercicio de la abogacía. Editorial Ariel, Ecuador (2014)

2. Constitución Política del Ecuador. Sangolquí, Quito - Ecuador. Derogada. 1998

3. Constitución de la República del Ecuador. Montecristi, Manabí-Ecuador. Vigente. 2008.

4. Código Orgánico de la Niñez y Adolescencia, Ecuador (2015)

5. Código Civil del Ecuador, (2015)

6. Código de Procedimiento Civil del Ecuador, (2014)

7. Código Orgánico Integral Penal del Ecuador (2014)

8. Código Orgánico General de Procesos, Ecuador (2015)

9. Carrillo V., Marco V.: "Deontología Jurídica y los Abogados", Casa de la Cultura Ecuatoriana "Benjamín Carrión", páginas 17 a 67 (2013)

10. Diccionario de la Real Academia de la lengua española - DRAE, 23a edición, publicada en Octubre de 2014. España.
11.Dioguardi Juana, La mediación en Argentina, (2013)

12.Ley de Arbitraje y Mediación, Ecuador. (2015)

13.Ley 26.589, Mediación y Conciliación de Argentina, (2013)

14. Martin Miguel A., Manual de mediación conciliación y arbitraje, edición Master, Buenos Aires, Argentina. (2012)

15. Revista Jurídica de Mediación, Instituto Complutense, UCM. España. (2010)

16. Revista Jurídica Mediación Familiar en Aragón, España. (2011)

17.Revista Jurídica Mediación Intrafamiliar, España. (2014)

\section{INTERNOGRAFÍA}

18.http://10tipos.com/tipos-de-conflictos/

19.http://es.wikipedia.org/wiki/Conflicto /

20.http://www.cejamericas.org/

21.Concurso_ponencias_semecuador2012/po nenciasseleccionadas.html.

22.http://www.anuvprogramas.org/resources/V ALORES\%20UNIVERSALES.pdf

23.www.esilec.com.ec a través del CNJ, 2015 